ITC $3 / 46$

Journal of Information Technology and Control

Vol. 46 / No. 3 / 2017

pp. 403-417

DOI 10.5755/j01.itc.46.3.14457

(C) Kaunas University of Technology
A Nonlinear Block-Oriented Model for Wind Tunnel System

Received 2016/03/25

Accepted after revision 2017/08/04

\title{
A Nonlinear Block-Oriented Model for Wind Tunnel System
}

\section{Tingfeng Zhang}

College of Information Science and Engineering, Northeastern University, Shenyang, 110819, China

College of Electrical Engineering, Liaoning University of Technology, Jinzhou, 121001, China

\section{Zhizhong Mao, Ping Yuan}

College of Information Science and Engineering, Northeastern University, Shenyang, 110819, China e-mail:maozhizhong@ise.neu.edu.cn

Corresponding author: maozhizhong@ise.neu.edu.cn

This paper develops a novel nonlinear block-oriented model for the wind tunnel system. Based on the available signals, the wind tunnel system can be divided into three parts, namely, the exhaust valve loop, the choke finger loop and the flow field. Then the considered plant is described as a nonlinear block-oriented model. The exhaust valve subsystem and the flow field subsystem are both expressed by linear dynamic models, whereas the choke finger subsystem exhibits a nonlinear characteristics and is approximated by a pseudo-Hammerstein model. Based on the above parameterization model, the recursive identification algorithms are presented for three subsystems. Interestingly, the adaptive weighted recursive least squares algorithm is applied to the pseudo-Hammerstein model, and the hierarchical recursive least squares algorithm is used to reduce the computational complexities. Both simulations and experiments are carried out to verify the effectiveness of the proposed method.

KEYWORDS: Wind tunnel system, block-oriented model, pseudo-Hammerstein model, recursive identification.

\section{Introduction}

The $2.4 \mathrm{~m}$ injector driven transonic wind tunnel is one of the major transonic facilities in China. It is one of the key tools for aerodynamic research on aircraft scale models. The aerodynamic data of scale models are used to study the effects of air moving past aircraft. The goal of this work is to establish a mathematical model for this process.
Modeling of a wind tunnel system is a multi-disciplinary field. It combines techniques of several domains such as aerodynamics, machines and electrical device. Due to complex internal structures, it is very difficult to obtain an accurate mechanism model for a wind tunnel [24]. On the other hand, some researchers have proposed data-driven methods to model 
wind tunnel systems. For instance, Jin et al. [7] developed a feature subsets based ensemble neural networks (ENN) nonlinear model and Rui et al. [22] presented a BP neural network based NARMAX model. The above methods both suffer heavy computational complexity problems [10], which may narrow their applicability for real-time control tasks. Moreover, the prediction accuracy is also affected by the number of training samples, which is another drawback of the data-driven methods.

It may be a more economical and feasible way to model the wind tunnel system based on a grey-box modeling scheme, for instance, a linear reduced order model with two inputs and two outputs is introduced for practical applications a decade ago [14]. However, with the development of space industry, more precise models are urgently needed since the simplified linear models cannot effectively capture dynamic behaviors of such complex processes.

In recent years, many researchers have devoted their efforts to accurate and fast modeling complex industrial processes. In the literature, many techniques such as multi-model representations [1], NARMAX models [8], Gaussian models [21,23], PCA models [13], neural networks [26], kernel methods [12] and fuzzy logic systems $[9,15,16,20]$ have turned out to be effective.

As an alternative, the block-oriented models, which consist of the interconnection of linear dynamic subsystems and static nonlinear elements, have gradually attracted numerous attentions of researchers. The main merits are reflected in computation time, minimal parameterization, initial model parameter guessing and physical insight [25]. Among this class, the most well known models are Hammerstein $(\mathrm{H})$ model, Wiener (W) model and Hammerstein-Wiener (H-W) model [19,30]. These block-oriented models have been proved to be useful in capturing the nonlinear behavior of many physical systems [5].

Inspired by the above pioneering results, this paper develops a nonlinear block-oriented model for the wind tunnel system. The considered plant is firstly divided into three parts, namely, the exhaust valve loop, the choke finger loop and the flow field. By analyzing the input-output characheristcs based on the available signals, the block-oriented model consists of three parts: 1) the exhaust valve subsystem that can be described by a single-input single output
(SISO) linear model and identified by the recursive least squares (RLS) algorithm; 2) the choke finger subsystyem that exhibits a nonlinear characteristics and can be approximated by a SISO pseudo-Hammerstein (pseudo-H) model. In order to cope with the hard nonlinearities, the adaptive weighted recursive least squares (AW-RLS) algorithm is applied based on the internal variable estimations. Moreover, by the use of an adaptive weighted factor, the convergence properties are also enhanced; 3) the flow field subsystem that can be described by a two-input two-output (TITO) linear model. Since the computational burden deteriorates greatly along with larger dimensions, the hierarchical recursive least squares (H-RLS) algorithm is used to address this problem. Based on the hierarchical concept, the flow field is simpilified into several sub-models with fewer parameters and smaller dimensions. Finally, numerical results are presented to validate the modeling scheme and show its merits over the previous ones.

The rest of the paper is organized as follows. Section 2 introduces the structure and operation principle of the wind tunnel. In Section 3, the block-oriented model and structure for the wind tunnel system is introduced. The parameter identification algorithms are formulated in Section 4. Simulation results illustrating the performance of the model and the algorithms are presented in Section 5. Finally, the conclusions are summarized in Section 6.

\section{Wind tunnel system description}

In this section, the wind tunnel system structure is firstly introduced. Then the analysis of the input-output characteristics of the exhaust valve loop, choke finger loop and flow field are presented, which lays a foundation for the nonlinear block-oriented model in Section 3.

\subsection{The wind tunnel system structure}

The simplified schematic structure of the $2.4 \mathrm{~m}$ wind tunnel is shown in Fig. 1. The storage tank is the high pressure air source and supply power for wind tunnel testing. The main pressure regulating valve is used to ensure the constant of the gas entering the wind tunnel. Thus there exists a closed control loop for main injector pressure. The scale model to be tested is set 


\section{Figurure 1}

The schematic structure of the $2.4 \mathrm{~m}$ wind tunnel

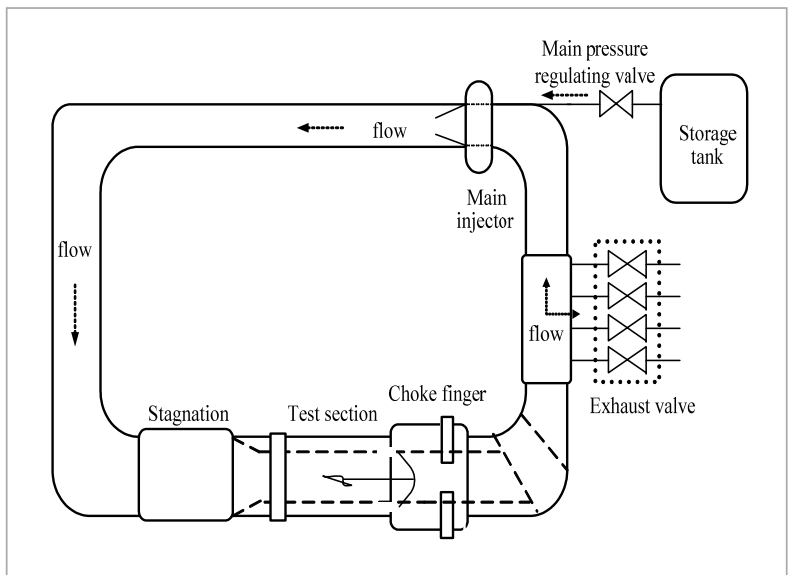

in the test section. The aerodynamic parameters of scale models are measured at given stagnation pressures and Mach numbers. The angle attack of scale model will change according to the test requirements after the flow field approaches steady, which will lead to the stagnation pressure and Mach number deviates from the set point. At the same time, the high-precision flow field is expected to recover by adjusting the main exhaust valve and the choke finger.

The high-speed air flow in the test section is generated and controlled by the wind tunnel. Some of the gas is exhausted through the main exhaust valve, while the rest continues to circle in the tunnel. Fig. 2 illustrates the inputs and outputs in wind tunnel system.
The stagnation pressure $\left(y_{1}\right)$ and the Mach number $\left(y_{2}\right)$ in the test section are two major controlled variables of the flow field.

\subsection{The input-output characteristics of the exhaust valve loop, choke finger loop and flow field}

The actuators of the wind tunnel are the main exhaust valve subsystem and choke finger subsystem. Each of the subsystems is composed of a hydraulic servomechanism including a control loop. These two subsystems are mutually independent. The structures of the exhaust valve loop and the choke finger loop are represented in Fig. 3 . The actual $\left(u_{1}, u_{2}\right)$ and outputs $\left(v_{1}, v_{2}\right)$ of the actuators are available. By analyzing the characteristics of the measured data, the exhaust valve loop has a linear behavior, and the choke finger loop has a nonlinear behavior.

The dynamic characteristics of the exhaust valve loop and the choke finger loop are neglected in the previous contributions $[7,10,22]$. However, the prediction accuracy and control performance may deteriorate if the dynamic characteristics of actuators are not fully considered, especially the inherent nonlinear behavior of the choke finger loop. To this end, by analyzing the mechanical features and input-output characteristics of the actuator, we try to introduce an input backlash into the modeling scheme. Later, the numerical results will verify the reasonableness of this novel idea. It is well known that backlash is particularly common in actuators, such as mechani-

\section{Figure 2}

The structure of the wind tunnel control system

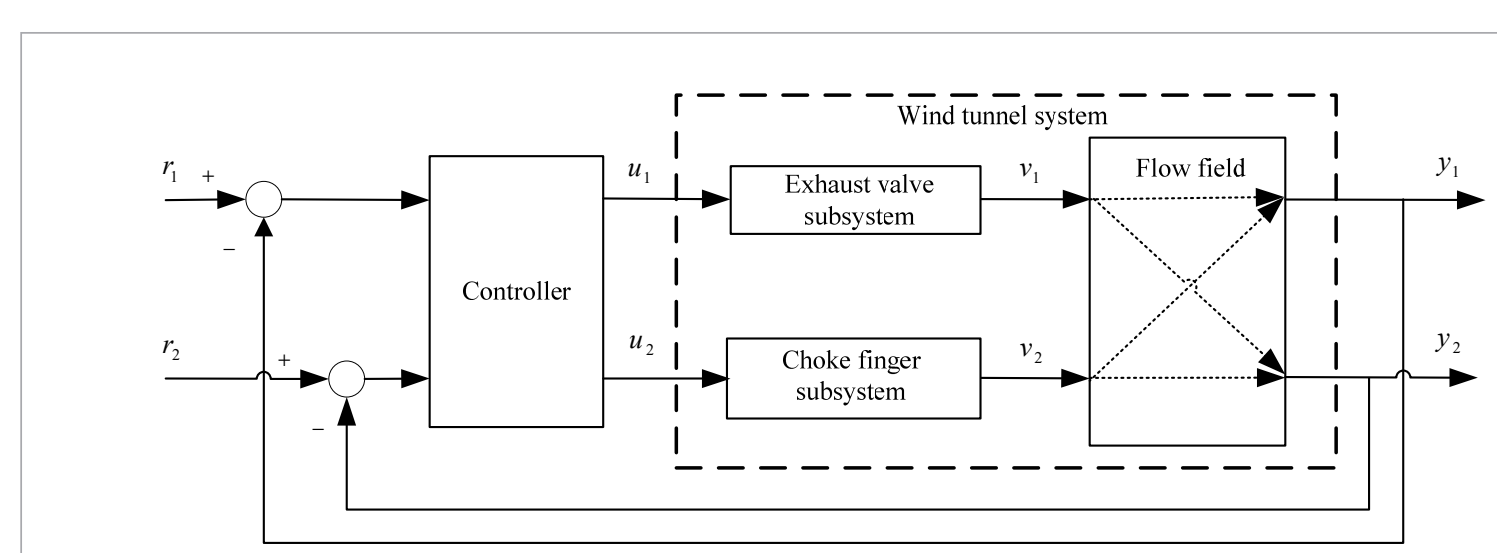


Figure 3

The structure of actuators

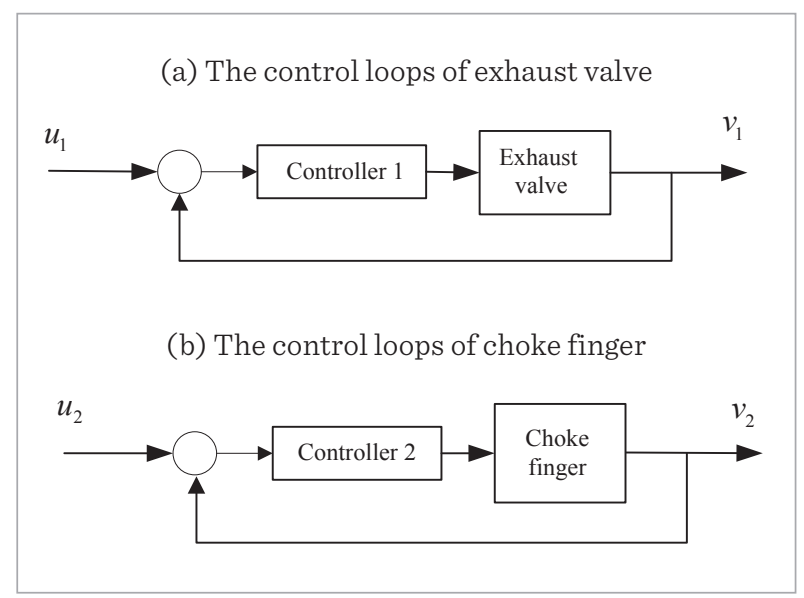

cal connections and hydraulic servo valves [27]. The actuator nonlinearity may often cause oscillations, delays and inaccuracy, and degrade the performance of control systems [6,18]. Many identification methods are proposed for systems with backlash nonlinearities [2,4,17].

In the flow field, there exists high pressure and high speed air flow during the wind tunnel testing. For the compressibility and viscidity of air in closed circuit, changing any of the actuators influences the stagnation pressure and Mach number. Then input-output characteristics of the flow field are represented in Fig. 4. This part can be considered as a TITO linear model.

\section{Modeling of the wind tunnel system}

In this section, the model of the wind tunnel is established based on the process actual data and structure characteristics. The online identification aims to achieve the following goals: 1 ) to predict the dynamic behaviors of the process; and 2) to lay foundation for an on-line control strategy.

\subsection{Block-oriented model of the wind tunnel}

By considering the backlash nonlinearity of the choke finger loop, the nonlinear block-oriented model is introduced into the wind tunnel system. The exhaust valve subsystem (S1) is represented by a linear model.

\section{Figure 4}

The input-output characteristics of the flow field
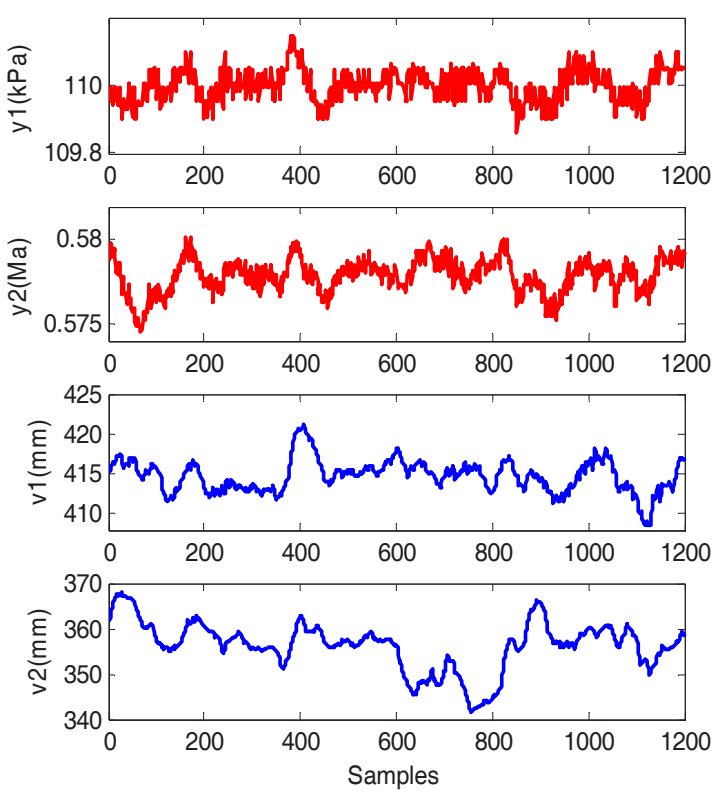

The choke finger subsystem (S2) is expressed as a pseudo-H model with input backlash. The coupled flow field subsystem (S3) is described as a TITO linear model. The block-oriented model diagram of the process is shown in Fig. 5.

For a wind tunnel, the signals $u_{1}$ and $u_{2}$ (the system inputs), $v_{1}$ and $v_{2}$ (the position of the exhaust valve and the choke finger), $y_{1}$ and $y_{2}$ (the system outputs) are measurable; the variable $x$ is the output of the backlash

\section{Figure 5}

The block-oriented model diagram of wind tunnel

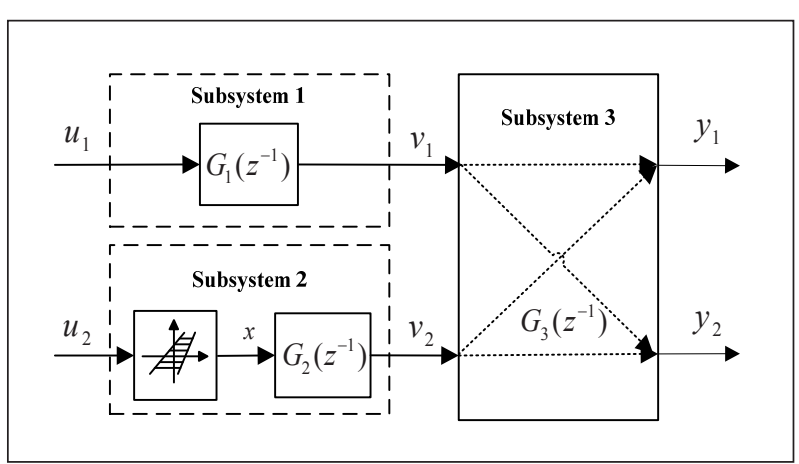


characteristic and is an unmeasurable intermediate signal; $G_{1}\left(z^{-1}\right), G_{2}\left(z^{-1}\right)$ and $G_{3}\left(z^{-1}\right)$ are linear transfer functions with the unit time delay operator $z^{-1}$.

\subsection{Modeling of the exhaust valve subsystem S1}

The following linear difference equation can describe the dynamics of the subsystem S1

$$
v_{1}(t)=\sum_{i=1}^{m e} b_{i} \cdot u_{1}(t-i)-\sum_{j=1}^{n e} a_{j} \cdot v_{1}(t-j)
$$

where $a_{1}, a_{2}, \cdots, a_{n e}, b_{1}, b_{2}, \cdots, b_{m e}$

are the parameters to be estimated. The orders me, ne are known a prior.

\subsection{Modeling of the choke finger subsystem S2}

A pseudo-H model with backlash is used to capture the dynamics of the subsystem S2. The input backlash of the pseudo-H model is shown in Fig. 6.

The mathematical models for the discrete-time case

\section{Figure 6}

An input-output map of backlash

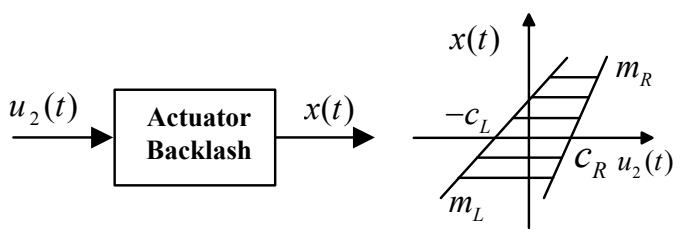

of the backlash characteristics are described by [5]

$$
x(t)=\left\{\begin{array}{l}
m_{L}\left[u_{2}(t)+c_{L}\right], \quad u_{2}(t)<z_{L} \\
x(t-1), \quad z_{L} \leq u_{2}(t) \leq z_{R} \\
m_{R}\left[u_{2}(t)-c_{R}\right], \quad u_{2}(t)>z_{R}
\end{array}\right.
$$

where $m_{L}, m_{R}, c_{L}>0, c_{R}>0$ are the unknown backlash parameters, and

$$
z_{L}=\frac{x(t-1)}{m_{L}}-c_{L}
$$

$$
z_{R}=\frac{x(t-1)}{m_{R}}+c_{R}
$$

are the $u$-axis values of the intersections, with the horizontal inner segment containing the slopes $m_{L}$ and $m_{R}$. In order to simplify the backlash description and estimate the backlash parameters, the switching function $h($.$) is defined as$

$$
h(s)= \begin{cases}0 & s>0 \\ 1 & s \leq 0 .\end{cases}
$$

To describe three branches of (2) in one equation, the following variables are defined for the description of backlash

$$
\begin{aligned}
f_{1}(t) & =h\left[u_{2}(t)-z_{L}\right] \\
= & h\left\{\left[m_{L} u_{2}(t)+m_{L} c_{L}-v_{2}(t-1)\right] / m_{L}\right\} \\
f_{2}(t) & =h\left[z_{R 2}-u_{2}(t)\right] \\
= & h\left\{\left[v_{2}(t-1)-m_{R} u_{2}(t)+m_{R} c_{R}\right] / m_{R}\right\} .
\end{aligned}
$$

In order to obtain the input and output parameters equations of the backlash input block, we rewrite (2) as

$$
\begin{aligned}
x(t)= & m_{L} u_{2}(t) f_{1}(t)+m_{L} c_{L} f_{1}(t)+m_{R} u_{2}(t) f_{2}(t) \\
& -m_{R} c_{R} f_{2}(t)+x(t-1)\left[1-f_{1}(t)\right]\left[1-f_{2}(t)\right] .
\end{aligned}
$$

It is clear that the linear part of the pseudo- $\mathrm{H}$ model can be written as follows:

$$
v_{2}(t)=G_{2}\left(z^{-1}\right) x(t)
$$

where the linear transfer functions $G_{2}\left(z^{-1}\right)$ are defined as follows

$$
G_{2}\left(z^{-1}\right)=\frac{\bar{b}_{1} z^{-1}+\bar{b}_{2} z^{-2}+\ldots+\bar{b}_{m f} z^{-m f}}{1+\bar{a}_{1} z^{-1}+\bar{a}_{2} z^{-2}+\ldots+\bar{a}_{n f} z^{-n f}}
$$

where $\bar{a}_{1}, \bar{a}_{2}, \cdots, \bar{a}_{n f}, \bar{b}_{1}, \bar{b}_{2}, \cdots, \bar{b}_{m f}$ are the unknown parameters to be estimated; $m f, n f$ are the orders of the linear block.

Substituting Eq. (8) into (9) yields the following input-output relationship

$$
v_{2}(t)=\sum_{i=1}^{m f} \bar{b}_{i} \cdot x_{2}(t-i)-\sum_{j=1}^{n f} \bar{a}_{j} \cdot v_{2}(t-j) .
$$




\subsection{Modeling of the flow field subsystem S3}

A multivariable coupled linear model is used to describe the dynamics of the subsystem S3. The inputs of the model are the positions of exhaust valve $\left(v_{1}\right)$ and choke finger $\left(v_{2}\right)$, and the outputs of the model are stagnation pressure $\left(y_{1}\right)$ and Mach number $\left(y_{2}\right)$. Then the flow field model $G_{3}\left(z^{-1}\right)$ is defined as

$$
\begin{aligned}
y_{1}(t)= & \sum_{i=1}^{n_{d}} b_{1 i}(t) v_{1}\left(t-d_{1}-i\right)+\sum_{j=1}^{n_{b}} b_{2 j}(t) v_{2}\left(t-d_{2}-j\right) \\
& +\sum_{k=1}^{n_{c}} a_{1 k}(t) y_{1}(t-k)+\sum_{l=1}^{n_{d}} a_{2 l}(t) y_{2}(t-l) \\
y_{2}(t)= & \sum_{i=1}^{\bar{n}_{d}} \bar{b}_{1 i}(t) v_{1}\left(t-\bar{d}_{1}-i\right)+\sum_{j=1}^{\bar{n}_{b}} \bar{b}_{2 j}(t) v_{2}\left(t-\bar{d}_{2}-j\right) \\
& +\sum_{k=1}^{\bar{n}_{c}} \bar{a}_{1 k}(t) y_{1}(t-k)+\sum_{l=1}^{\bar{n}_{d}} \bar{a}_{2 l}(t) y_{2}(t-l)
\end{aligned}
$$

where $b_{1 i}(t), b_{2 j}(t), a_{1 k}(t), a_{2 l}(t), \bar{b}_{1 i}(t), \bar{b}_{2 j}(t), \bar{a}_{1 k}(t)$, $\bar{a}_{2 l}(t)$ are the unknown parameters. The orders $n_{a}, n_{b}$, $n_{c}, n_{d}, \bar{n}_{a}, \bar{n}_{b}, \bar{n}_{c}, \bar{n}_{d}$ and the time delays $d_{1}, d_{2}, \bar{d}_{1}, \bar{d}_{2}$ are assumed to be known.

\section{Parameter estimation scheme}

Parameter estimation is based on available data measured from the wind tunnel process. Three suitable recursive identification methods are applied to these subsystems.

\subsection{Parameter estimation for exhaust valve subsystem}

To estimate the parameters in (1), the recursive identification algorithm [11] has been used. Define the following parameter and data vectors:

$$
\begin{aligned}
\theta_{v 1}= & {\left[b_{1}, b_{3}, \ldots b_{m e}, a_{1}, a_{2}, \ldots a_{n e}\right]^{T} } \\
\phi_{v 1}(t)= & {\left[u_{1}(t-1), u_{1}(t-2), \ldots, u_{1}(t-m e),\right.} \\
& \left.-v_{1}(t-1),-v_{1}(t-2), \ldots-v_{1}(t-n e)\right]^{T} .
\end{aligned}
$$

The output equation (1) can be rewriten in a compact form

$$
v_{1}(t)=\varphi_{v 1}^{T}(t) \theta_{v 1} .
$$

The estimates of parameter vector can be evaluated using the RLS algrithm. Firstly, define the output error

$e_{v 1}(t)=v_{1}(t)-\phi_{v 1}^{T}(t) \hat{\theta}_{v 1}(t)$

based on (16), where $\hat{\theta}_{v 1}(t)$ is the estimate of the parameter vector $\theta_{v 1}(t)$.

Then the recursive identification algorithm is as follows:

$$
\hat{\theta}_{v 1}(t)=\theta_{v 1}(t-1)+K_{v 1}(t) e_{v 1}(t)
$$

$$
K_{v 1}(t)=\frac{P_{v 1}(t-1) \phi_{v 1}(t)}{\lambda_{v 1}+\phi_{v 1}^{T}(t) P_{v 1}(t-1) \phi_{v 1}(t)}
$$

$$
P_{v 1}(t)=P_{v 1}(t-1)-K_{v 1}(t) \phi_{v 1}^{T}(t) P_{v 1}(t-1)
$$

where $\theta_{v 1}=\left[\hat{b}_{1}, b_{3}, \ldots b_{m e}, \hat{a}_{1}, a_{2}, \ldots a_{n e}\right]^{T}$. To initialize the recursive algorithmin (17)-(20), we take $P_{v 1}(0)=\mu_{v 1} I$, $\hat{\theta}_{v 1}(0)=\varepsilon_{v 1} \times[1,1, \cdots 1]$, where $\mu_{v 1} \in\left[10^{4}, 10^{10}\right]$, I is the unit matrix, $\varepsilon_{v 1}, \lambda_{v 1} \leq 1$ is the weighting term.

\subsection{Parameter estimation for choke finger subsystem}

The AW-RLS method [29] is used to estimate the parameters of the pseudo-H model.

The output equation of (11) is a very complex expression. In order to obtain the separated variable $x(t-1)$, according to the key term separation principle [21], we can assume without loss of generality that $\bar{b}_{1}=1$ in (11). Then substituting (8) into (11) yields the following equation:

$$
\begin{aligned}
v_{2}(t)= & m_{L} u_{2}(t-1) f_{1}(t-1)+m_{L} c_{L} f_{1}(t-1) \\
& +m_{R} u_{2}(t-1) f_{2}(t-1)-m_{R} c_{R} f_{2}(t-1) \\
& +x_{2}(t-2)\left[1-f_{1}(t-1)\right]\left[1-f_{2}(t-1)\right] \\
& +\bar{b}_{2} x(t-2)+\bar{b}_{3} x(t-3) \cdots+\bar{b}_{m f} x(t-m f) \\
& -\bar{a}_{1} v_{2}(t-1)-\bar{a}_{2} v_{2}(t-2) \ldots-\bar{a}_{n f} v_{2}(t-n f) .
\end{aligned}
$$

Define the unknown parameter vector $\theta_{v 2}$

$$
\begin{aligned}
\theta_{v 2}= & {\left[m_{L}, m_{L} c_{L}, m_{R}, m_{R} c_{R},\right.} \\
& \left.\bar{b}_{2}, \bar{b}_{3}, \ldots \bar{b}_{m f}, \bar{a}_{1}, \bar{a}_{2}, \ldots \bar{a}_{n f}\right]^{T}
\end{aligned}
$$


and the information vector $\phi_{v 2}(t)$

$$
\begin{aligned}
& \varphi_{v 2}(t)=\left[u_{2}(t-1) f_{1}(t-1), f_{1}(t-1),\right. \\
& u_{2}(t-1) f_{2}(t-1),-f_{2}(t-1), x(t-2), \\
& x(t-3), \ldots, x(t-m f),-v_{2}(t-1), \\
& \left.-v_{2}(t-2), \ldots,-v_{2}(t-n f)\right]^{T} .
\end{aligned}
$$

Then the parameterized pseudo-H model (21) can be rewritten as follows:

$$
v_{2}(t)-x(t-2)\left[1-f_{1}(t-1)\right]\left[1-f_{2}(t-1)\right]=\varphi_{v 2}{ }^{T}(t) \theta_{v 2} .
$$

In order to estimate the parameters, we introduce the estimates $\hat{\theta}_{v 2}$ of the parameter vector $\theta_{v 2}$

$$
\begin{aligned}
\hat{\theta}_{v 2}(t)= & {\left[\hat{m}_{L}(t), m_{L}(t) c_{L}(t), m_{R}(t),\right.} \\
& \hat{m}_{R}(t) c_{R}(t), \hat{\bar{b}}_{2}(t), \bar{b}_{3}(t), \ldots, \\
& \left.\hat{\bar{b}}_{m f}(t), \hat{\bar{a}}_{1}(t), \bar{a}_{2}(t), \ldots, \bar{a}_{n f}(t)\right]^{T} .
\end{aligned}
$$

The predicted output at time $t$ is

$$
\begin{aligned}
\hat{v}_{2}(t)= & \varphi_{v 2}{ }^{T}(t) \hat{\theta}_{v 2}(t-1) \\
& +x(t-2)\left[1-f_{1}(t-1)\right]\left[1-f_{2}(t-1)\right] .
\end{aligned}
$$

The output error is

$$
\begin{aligned}
e_{v 2}(t) & =v_{2}(t)-\varphi_{v 2}{ }^{T}(t) \hat{\theta}_{v 2}(t-1) \\
& -x(t-2)\left[1-f_{1}(t-1)\right]\left[1-f_{2}(t-1)\right] .
\end{aligned}
$$

Providing that the internal auxiliary variables $\left\{f_{1}(t), f_{2}(t), x(t)\right\}_{t=1,2}$ are totally known, based on (23)-(27), we can update $\hat{\theta}_{v 2}(t)$ according to the following weighted RLS algorithm

$$
\begin{aligned}
e_{v 2}(t)= & v_{2}(t)-\varphi_{v 2}{ }^{T}(t) \hat{\theta}_{v 2}(t-1) \\
- & x(t-2)\left[1-f_{1}(t-1)\right]\left[1-f_{2}(t-1)\right] . \\
\hline P_{v 2}(t)= & P_{v 2}(t-1) \\
- & \frac{P_{v 2}(t-1) \varphi_{v 2}(t) \varphi_{v 2}^{T}(t) P_{v 2}(t-1)}{\lambda_{v 2}(t)+\varphi_{v 2}^{T}(t) P_{v 2}(t-1) \varphi_{v 2}(t)} \\
\hat{\theta}_{v 2}(t)= & {\left[\hat{m}_{L}(t), m_{L}(t) c_{L}(t), m_{R}(t),\right.} \\
& \hat{m}_{R}(t) c_{R}(t), \hat{\bar{b}}_{2}(t), \bar{b}_{3}(t), \ldots, \\
& \left.\hat{\bar{b}}_{m f}(t), \hat{\bar{a}}_{1}(t), \bar{a}_{2}(t), \ldots, \bar{a}_{n f}(t)\right]^{T}
\end{aligned}
$$

where $\lambda_{v 2}(t)$ is the weighting term.

However, since the true innovation $e_{v 2}(t)$ and the information vector $\varphi_{v 2}(t)$ contain internal auxiliary variables $\left\{f_{1}(t), f_{2}(t), x(t)\right\}_{t=1,2, \ldots}$, which are generally unmeasurable. Thus the parameter estimation cannot be performed directly on the basis of (28)-(30).

Motivated by the ideas in [27], we replace the true counterparts $e_{v 2}(t)$ and $\varphi_{v 2}(t)$ with the estimated innovation $\hat{e}_{v 2}(t)$ and the estimated information vector $\hat{\varphi}_{v 2}(t)$. The internal variable estimations $\left\{\hat{f}_{1}(t), f_{2}(t), \hat{x}(t)\right\}_{t=1,2, \ldots}$ are used to derive $\hat{e}_{v 2}(t)$ and $\hat{\varphi}_{v 2}(t)$. Then, the AW-RLS algorithm based on the internal variables estimations is as follows:

$$
\begin{aligned}
& \hat{\theta}_{v 2}(t)=\theta_{v 2}(t-1) \\
& +\frac{P_{v 1}(t-1) \hat{\varphi}_{2}(t) e_{v 2}(t)}{\lambda_{v 2}(t)+\hat{\varphi}_{v 2}^{T}(t) P_{v 2}(t-1) \varphi_{v 2}(t)} \\
& P_{v 2}(t)=P_{v 2}(t-1) \\
& -\frac{P_{v 2}(t-1) \hat{\varphi}_{v 2}(t) \varphi_{v 2}^{T}(t) P_{v 2}(t-1)}{\lambda_{v 2}+\hat{\varphi}_{v 2}^{T}(t) P_{v 2}(t-1) \varphi_{v 2}(t)} \\
& \hat{e}_{v 2}(t)=v_{2}(t)-\hat{\varphi}_{v 2}{ }^{T}(t) \hat{\theta}_{v 2}(t-1) \\
& -x(t-2)\left[1-\hat{f}_{1}(t-1)\right]\left[1-f_{2}(t-1)\right] \\
& \hat{\varphi}_{v 2}(t)=\left[u_{2}(t-1) \hat{f}_{1}(t-1), f_{1}(t-1),\right. \\
& u_{2}(t-1) \hat{f}_{2}(t-1),-f_{2}(t-1), \hat{x}(t-2) \text {, } \\
& \hat{x}(t-3), \ldots x(t-m f),-v_{2}(t-1) \text {, } \\
& \left.-v_{2}(t-2), \ldots-v_{2}(t-n f)\right]^{T}
\end{aligned}
$$$$
\hat{f}_{1}(t)=h\left\{\left[\hat{m}_{L}(t) u_{2}(t)+m_{L}(t) c_{L}(t)\right.\right.
$$$$
\left.-\hat{x}(t-1)] / m_{L}(t)\right\}
$$

$$
\begin{aligned}
\hat{f}_{2}(t) & =h\left\{\left[\hat{x}(t-1)-m_{R}(t) u_{2}(t)\right.\right. \\
& \left.\left.+\hat{m}_{R}(t) c_{R}(t)\right] / m_{R}(t)\right\}
\end{aligned}
$$

$$
\begin{aligned}
\hat{x}(t)= & m_{L}(t) u_{2}(t) \hat{f}_{1}(t)+m_{L}(t) c_{L}(t) f_{1}(t) \\
& +\hat{m}_{R}(t) u_{2}(t) \hat{f}_{2}(t)-m_{R}(t) c_{R}(t) f_{2}(t) \\
& +\hat{x}(t-1)\left[1-\hat{f}_{1}(t)\right]\left[1-f_{2}(t)\right] .
\end{aligned}
$$

The internal variable estimations are updated by (35)-(37). Motivated by [29], for the algorithm (31)(34), in order to enhance the convergence and tolerate large initial estimation errors, $\lambda_{v 2}(t)$ is suggested to be chosen as an adaptive form 


$$
\lambda_{v 2}(t)=\varepsilon_{1} \hat{\phi}_{v 2}^{T}(t) P_{v 2}(t) \phi_{v 2}(t)+\varepsilon_{2}
$$

where $\varepsilon_{1}$ and $\varepsilon_{2}$ are positive real numbers. At the beginning of the identification process, especially for bad initial conditions, a larger $\varepsilon_{1}$ is beneficial to convergence properties. On the other hand, the term $\varepsilon_{1} \hat{\phi}_{v 2}^{T}(t) P_{v 2}(t) \phi_{v 2}(t)$ tends to zero as the estimates approach the true values. Inevitably, a small $\varepsilon_{2}$ is also required to guarantee a high convergence speed.

To initialize the recursive algorithm in (31)-(34), we take $P_{v 2}(0)=\rho_{v 21} I$, where $\rho_{v 21}$ is a large positive scalar, e.g., $\rho_{v 21}=10^{5}$ and $\hat{\theta}_{v 2}(0)=\rho_{v 22} \times[1,1, \cdots, 1]^{T}$, where $\rho_{v 22}$ is a small positive scalar, e.g., $\rho_{v 22}=10^{-2}$.

\subsection{Parameter estimation for the flow field subsystem}

The wind tunnel is a rapid sampling system and the sampling time is $10 \mathrm{~ms}$ to $50 \mathrm{~ms}$. According to the principle of aerodynamics and the analysis of the actual data, the variation between adjacent elements sampling interval is small. Therefore, the flow field subsystem can be considered as a TITO slowly time-varying linear process.

Since the computational burden deteriorates greatly along with larger dimensions, the H-RLS algorithm is used to address this problem. The basic idea of H-RLS is to decompose the identification model into several sub-models with fewer parameters and smaller dimensions. It is proven that the H-RLS algorithm retains much less computational burden than the RLS algorithm [3, 28].

Then the flow field subsystem is identified by the following H-RLS algorithm.

\section{Step1. Decomposition}

Define the parameter vectors $\theta_{w 1}(t), \theta_{w 2}(t)$, and the information vectors $\varphi_{w 1}(t), \varphi_{w 1}(t)$ for the wind tunnel flow field in (20) and (21)

$$
\begin{array}{r}
\theta_{w 1}(t)=\left[a_{11}(t), \cdots, a_{1 n_{a}}(t), a_{21}(t), \cdots, a_{2 n_{b}}(t),\right. \\
\left.b_{11}(t), \cdots, b_{1 n_{c}}(t), b_{21}(t), \cdots, b_{2 n_{d}}(t)\right]^{T} \\
\theta_{w 2}(t)=\left[\bar{a}_{11}(t), \cdots, \bar{a}_{1 \bar{n}_{a}}(t), \bar{a}_{21}(t), \cdots, \bar{a}_{2 \bar{n}_{b}}(t),\right. \\
\left.\bar{b}_{11}(t), \cdots, \bar{b}_{1 \bar{n}_{c}}(t), \bar{b}_{21}(t), \cdots, \bar{b}_{2 \bar{n}_{d}}(t)\right]^{T}
\end{array}
$$

$$
\begin{aligned}
\varphi_{w 1}(t)= & {\left[y_{1}(t-1), \cdots, y_{1}\left(t-n_{a}\right), y_{2}(t-1), \cdots,\right.} \\
& y_{2}\left(t-n_{b}\right), v_{1}\left(t-d_{1}\right), \cdots, v_{1}\left(t-d_{1}-n_{c}\right), \\
& \left.v_{2}\left(t-d_{2}\right), \cdots, v_{2}\left(t-d_{2}-n_{d}\right)\right]^{T} \\
\varphi_{w 2}(t)= & {\left[y_{1}(t-1), \cdots, y_{1}\left(t-\bar{n}_{a}\right), y_{2}(t-1), \cdots,\right.} \\
& y_{2}\left(t-\bar{n}_{b}\right), v_{1}\left(t-\bar{d}_{1}\right), \cdots, v_{1}\left(t-\bar{d}_{1}-\bar{n}_{c}\right), \\
& \left.v_{2}\left(t-\bar{d}_{2}\right), \cdots, v_{2}\left(t-\bar{d}_{2}-\bar{n}_{d}\right)\right]^{T} .
\end{aligned}
$$

Equations (12) and (13) can be rewritten in a regressive form

$$
y_{1}(t)=\varphi_{w 1}^{T}(t) \theta_{w 1}(t)
$$

$$
y_{2}(t)=\varphi_{w 2}^{T}(t) \theta_{w 2}(t) .
$$

The system in (43) and (44) is decomposed into two subsystems, respectively, and consequently the parameter vectors $\theta_{w 1}(t)$ and $\theta_{w 2}(t)$ are decomposed into two sub-parameter vectors

$$
\theta_{w 1}(t)=\left[\theta_{w 1 a}^{T}(t), \theta_{w 1 b}^{T}(t)\right]^{T}
$$

$$
\theta_{w 2}(t)=\left[\theta_{w 2 a}^{T}(t), \theta_{w 2 b}^{T}(t)\right]^{T}
$$

and the information vectors $\varphi_{w 1}(t)$ and $\varphi_{w 2}(t)$ are decomposed into two sub-information vectors

$$
\varphi_{w 1}(t)=\left[\varphi_{w 1 y}^{T}(t), \varphi_{w 1 v}^{T}(t)\right]^{T}
$$

$$
\varphi_{w 2}(t)=\left[\varphi_{w 2 y}^{T}(t) ; \varphi_{w 2 v}^{T}(t)\right]^{T}
$$

where the vectors $\theta_{w 1 a}(t), \theta_{w 1 b}(t), \theta_{w 2 a}(t), \theta_{w 2 b}(t)$, $\varphi_{w 1 y}(t), \varphi_{w 1 v}(t), \varphi_{w 2 y}(t)$ and $\varphi_{w 2 v}(t)$ in (46)-(49) are defined as follows

$$
\theta_{w 1 a}(t)=\left[a_{11}(t), \cdots, a_{1 n_{a}}(t), a_{21}(t), \cdots, a_{2 n_{b}}(t)\right]^{T}
$$

$$
\theta_{w 1 b}(t)=\left[b_{11}(t), \cdots, b_{1 n_{c}}(t), b_{21}(t), \cdots, b_{2 n_{d}}(t)\right]^{T}
$$

$\theta_{w 2 a}(t)=\left[\bar{a}_{11}(t), \cdots, \bar{a}_{1 \bar{n}_{a}}(t), \bar{a}_{21}(t), \cdots, \bar{a}_{2 \bar{n}_{b}}(t)\right]^{T}$

$$
\theta_{w 2 b}(t)=\left[\bar{b}_{11}(t), \cdots, \bar{b}_{1 \bar{n}_{c}}(t), \bar{b}_{21}(t), \cdots, \bar{b}_{2 \bar{n}_{d}}(t)\right]^{T}
$$

$\varphi_{w 1 y}(t)=\left[y_{1}(t-1), \cdots, y_{1}\left(t-n_{a}\right)\right.$,

$$
\left.y_{2}(t-1), \cdots, y_{2}\left(t-n_{b}\right)\right]^{T}
$$




$$
\begin{gathered}
\varphi_{w 1 v}(t)=\left[\begin{array}{c}
v_{1}\left(t-d_{1}\right), \cdots, v_{1}\left(t-d_{1}-n_{c}\right), \\
\left.v_{2}\left(t-d_{2}\right), \cdots, v_{2}\left(t-d_{2}-n_{d}\right)\right]^{T}
\end{array}\right. \\
\hline \varphi_{w 2 y}(t)=\left[\begin{array}{c}
y_{1}(t-1), \cdots, y_{1}\left(t-\bar{n}_{a}\right), \\
\left.y_{2}(t-1), \cdots, y_{2}\left(t-\bar{n}_{b}\right)\right]^{T}
\end{array}\right. \\
\varphi_{w 2 v}(t)=\left[\begin{array}{c}
v_{1}\left(t-\bar{d}_{1}\right), \cdots, v_{1}\left(t-\bar{d}_{1}-\bar{n}_{c}\right), \\
\left.v_{2}\left(t-\bar{d}_{2}\right), \cdots, v_{2}\left(t-\bar{d}_{2}-\bar{n}_{d}\right)\right]^{T} .
\end{array}\right.
\end{gathered}
$$

According to the H-RLS principle [29], the equations (43) and (44) can be written in the following hierarchical forms

\begin{tabular}{l}
\hline$y_{1}(t)-\varphi_{w 1 v}^{T}(t) \theta_{w 1 b}(t)=\varphi_{w 1 y}^{T}(t) \theta_{w 1 a}(t)$ \\
\hline$y_{1}(t)-\varphi_{w 1 y}^{T}(t) \theta_{w 1 a}(t)=\varphi_{w 1 v}^{T}(t) \theta_{w 1 b}(t)$ \\
$y_{2}(t)-\varphi_{w 2 y}^{T}(t) \theta_{w 2 a}(t)=\varphi_{w 2 v}^{T}(t) \theta_{w 2 b}(t)$ \\
$y_{2}(t)-\varphi_{w 2 y}^{T}(t) \theta_{w 2 a}(t)=\varphi_{w 2 v}^{T}(t) \theta_{w 2 b}(t)$
\end{tabular}

Step2. Sub-models identification

According to the recursive least squares principle, we can derive the identification algorithm for each subsystem. Let $\hat{\theta}_{w 1 a}(t), \hat{\theta}_{w 1 b}(t), \hat{\theta}_{w 2 a}(t)$ and $\hat{\theta}_{w 2 b}(t)$ denote the estimates of the parameter vectors in (49)-(52).

$$
\begin{aligned}
& \hat{\theta}_{w 1 a}(t)=\left[\hat{a}_{11}(t), \cdots, a_{1 n_{a}}(t), a_{21}(t), \cdots, a_{2 n_{b}}(t)\right]^{T} \\
& \hat{\theta}_{w 1 b}(t)=\left[\hat{b}_{11}(t), \cdots, b_{1 n_{c}}(t), b_{21}(t), \cdots, b_{2 n_{d}}(t)\right]^{T} \\
& \hat{\theta}_{w 2 a}(t)=\left[\hat{\bar{a}}_{11}(t), \cdots, \bar{a}_{1 \bar{n}_{a}}(t), \bar{a}_{21}(t), \cdots, \bar{a}_{2 \bar{n}_{b}}(t)\right]^{T} \\
& \hat{\theta}_{w 2 b}(t)=\left[\hat{\bar{b}}_{11}(t), \cdots, \bar{b}_{1 \bar{n}_{c}}(t), \bar{b}_{21}(t), \cdots, \bar{b}_{2 \bar{n}_{d}}(t)\right]^{T} .
\end{aligned}
$$

For the hierarchical models (57) and (58), the parameter estimates can be updated as follows

$$
\begin{aligned}
& \hat{\theta}_{w 1 a}(t)=\theta_{w 1 a}(t-1)+P_{1}(t) \varphi_{w 1 y}(t) \times\left[y_{1}(t)\right. \\
& \left.-\varphi_{w 1 v}^{T}(t) \theta_{w 1 b}(t)-\phi_{w 1 y}^{T}(t) \hat{\theta}_{w 1 a}(t-1)\right] \\
& P_{1}(t)=P_{1}(t-1)-\frac{P_{1}(t-1) \varphi_{w 1 y}(t) \varphi_{w 1 y}^{T}(t) P_{1}(t-1)}{1+\varphi_{w 1 y}^{T}(t) P_{1}(t-1) \varphi_{w 1 y}(t)} \\
& \hat{\theta}_{w 1 b}(t)=\theta_{w 1 b}(t-1)+P_{2}(t) \varphi_{w 1 v}(t) \times\left[y_{1}(t)\right. \\
& \left.-\varphi_{w 1 y}^{T}(t) \theta_{w 1 a}(t)-\phi_{w 1 v}^{T}(t) \hat{\theta}_{w 1 b}(t-1)\right]
\end{aligned}
$$

$$
P_{2}(t)=P_{2}(t-1)-\frac{P_{2}(t-1) \varphi_{w 1 v}(t) \varphi_{w 1 v}^{T}(t) P_{1}(t-1)}{1+\varphi_{w 1 v}^{T}(t) P_{1}(t-1) \varphi_{w 1 v}(t)}
$$

where $P_{1}(t)$ and $P_{2}(t)$ are the covariance matrix of the sub-models. However, there is a difficulty that the equations (65) and (67) contain unknown parameter vectors. Then, by means of the coordination idea based on the hierarchical identification principle, we present a new algorithm to deal with the problem.

\section{Step3. Coordination}

The coordination idea is to replace the unknown vectors $\theta_{w 1 a}(t)$ and $\theta_{w 1 b}(t)$ which appear in (65) and $(67)$ by their corresponding estimates $\hat{\theta}_{w 1 a}(t-1)$ and $\hat{\theta}_{w 1 b}(t-1)$ at the preceding time, so we have

$$
\begin{array}{r}
\begin{array}{r}
\hat{\theta}_{w 1 a}(t)= \\
\theta_{w 1 a}(t-1)+P_{1}(t) \varphi_{w 1 y}(t) \times\left[y_{1}(t)\right. \\
\left.-\varphi_{w 1 v}^{T}(t) \hat{\theta}_{w 1 b}(t-1)-\phi_{w 1 y}^{T}(t) \theta_{w 1 a}(t-1)\right]
\end{array} \\
P_{1}(t)=P_{1}(t-1)-\frac{P_{1}(t-1) \varphi_{w 1 y}(t) \varphi_{w 1 y}^{T}(t) P_{1}(t-1)}{1+\varphi_{w 1 y}^{T}(t) P_{1}(t-1) \varphi_{w 1 y}(t)}
\end{array}
$$

$$
\begin{aligned}
\hat{\theta}_{w 1 b}(t)= & \theta_{w 1 b}(t-1)+P_{2}(t) \varphi_{w 1 v}(t) \times\left[y_{1}(t)\right. \\
& \left.-\varphi_{w 1 y}^{T}(t) \theta_{w 1 a}(t-1)-\phi_{w 1 v}^{T}(t) \hat{\theta}_{w 1 b}(t-1)\right]
\end{aligned}
$$

$$
P_{2}(t)=P_{2}(t-1)-\frac{P_{2}(t-1) \varphi_{w 1 v}(t) \varphi_{w 1 v}^{T}(t) P_{1}(t-1)}{1+\varphi_{w 1 v}^{T}(t) P_{1}(t-1) \varphi_{w 1 v}(t)} .
$$

Then, we can get the parameter estimates $\hat{\theta}_{w 1 a}$ and $\hat{\theta}_{w 1 b}$. To initialize the H-RLS algorithm, we take $P_{1}(0)=\mu_{1} I, \quad \hat{\theta}_{w 1 a}(0)=\varepsilon_{1}[1,1, \ldots, 1]^{T}, \quad P_{2}(0)=\mu_{2} I \quad$ and $\hat{\theta}_{w 1 b}(0)=\varepsilon_{2}[1,1, \ldots, 1]^{T}$, where $\mu_{1}$ and $\mu_{2}$ are large positive scalars, e.g., $\mu_{1}, \mu_{2} \in\left[10^{4}, 10^{10}\right]$. $I$ is the unit matrix, $\varepsilon_{1}$ and $\varepsilon_{2}$ are small positive scalars.

In the same way, we can obtain the parameter estimates $\hat{\theta}_{w 2 a}$ and $\hat{\theta}_{w 2 b}$.

\section{Model test and application}

The main purpose of this section is to evaluate the proposed model and identification algorithms. To achieve this goal, MATLAB simulations and control platform real-time verification are both carried out.

In the following, two performance evaluation criteria are used, namely, the root mean square error 
(RMSE) and Maximum absolute error (MAE). These performance criteria are defined as follows:

$$
R M S E=\sqrt{\frac{\sum_{t=1}^{N}(\hat{y}(t)-y(t))^{2}}{N}}
$$

$$
M A E=\max \{|\hat{y}(t)-y(t)|, t=1 \cdots N\}
$$

where $\hat{y}(t)$ denotes the predictive value, $y(t)$ denotes the actual value, $N$ is the number of validation data.

\subsection{Simulation and verification}

The data of two operating conditions are used for parameter estimation and model verification. These two operating conditions are: 1) stagnation pressure $110 \mathrm{kPa}$, Mach number 0.578, and 2) stagnation pressure $130 \mathrm{kPa}$, Mach number 0.822. In this section, the sampling period is selected as $50 \mathrm{~ms}$.

The orders of the systems are determined by the false nearest neighbor algorithm [22]. Therefore, we choose $m e=n e=1, m f=1, n f=2, n_{a}=n_{b}=n_{c}=n_{d}=2$ and $\bar{n}_{a}=\bar{n}_{b}=\bar{n}_{c}=\bar{n}_{d}=2$. We select the time delay $d_{1}, d_{2}$, $\bar{d}_{1}$ and $\bar{d}_{2}$ as 1 . The parameter estimation results of the exhaust valve subsystem and the choke finger subsystem are shown in Figs. 7-8 and Table 1. The unit of the parameters $c_{L}, c_{R}$ is mm (millimeter). From the identification results, we can see that it is reasonable to introduce the backlash nonlinearity into the choke finger loop.

\section{Figure 7}

Estimations of exhaust valve
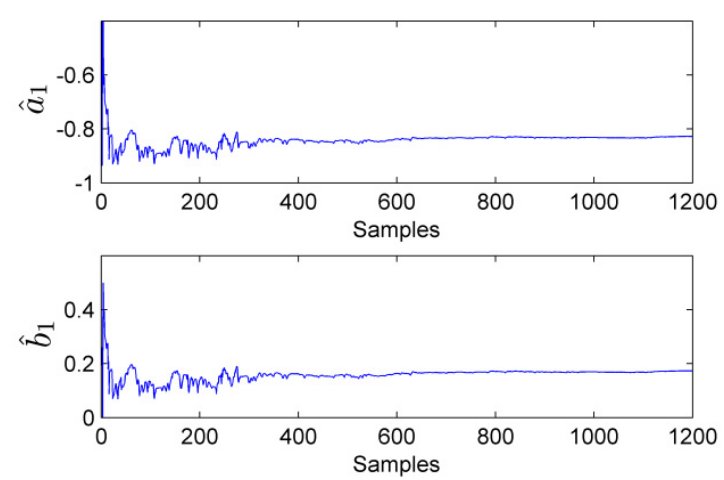

\section{Figure 8}

Estimations of the choke finger model

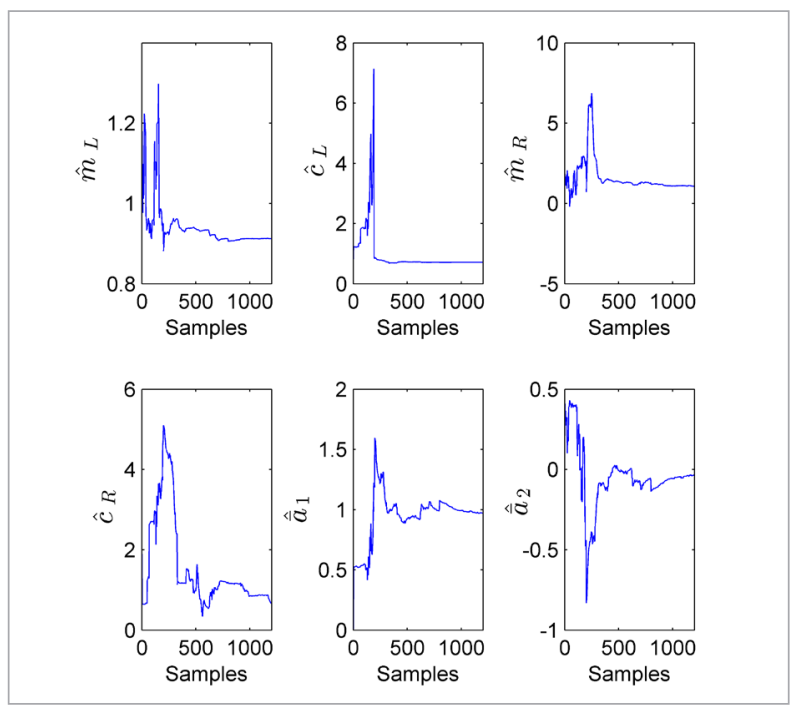

Table 1

The convergent parameter estimates of the exhaust valve and choke finger models

\begin{tabular}{c|c|c|c|c|c|c|c}
\hline \multicolumn{1}{c|}{ exhaust valve } & \multicolumn{1}{c}{ choke finger } \\
\hline$\hat{a}_{1}$ & $\hat{b}_{1}$ & $\hat{m}_{L}$ & $\hat{m}_{R}$ & $\hat{C}_{L}$ & $\hat{C}_{R}$ & $\hat{\bar{a}}_{1}$ & $\hat{\bar{a}}_{2}$ \\
\hline-0.62 & 0.39 & 0.9 & 0.9 & 0.8 & 0.85 & 1.0 & -0.17 \\
\hline
\end{tabular}

Fig. 9 shows the comparision results between the actual outputs and the predicted outputs of the identified exhaust valve subsystem and the choke finger subsystem. The former plot is the true (-) and predicted $(\cdots)$ outputs for the exhaust valve subsystem. The latter plot is the true $(-)$ and predicted $(\cdots)$ outputs for the choke finger subsystem. This illustrates that the fitting performance between the predicted outputs and the actual outputs are satisfactory.

The parameter estimation results of the flow field are shown in Figs. 10-11. Note that Fig. 10 depicts the stagnation pressure parameter estimates of equation (40), and Fig. 11 depicts the Mach number parameter estimates of equation (41).

The comparisons between the measured values and the estimated values of stagnation pressure and Mach 
number are shown in Figs. 12-13. It can be seen that the estimated outputs fit the measured data well. The comparison results between the proposed blockoriented model, ENN model and the conventional

\section{Figure 9}

Measured and predicted outputs of the identified exhaust valve subsystem and the choke finger subsystem

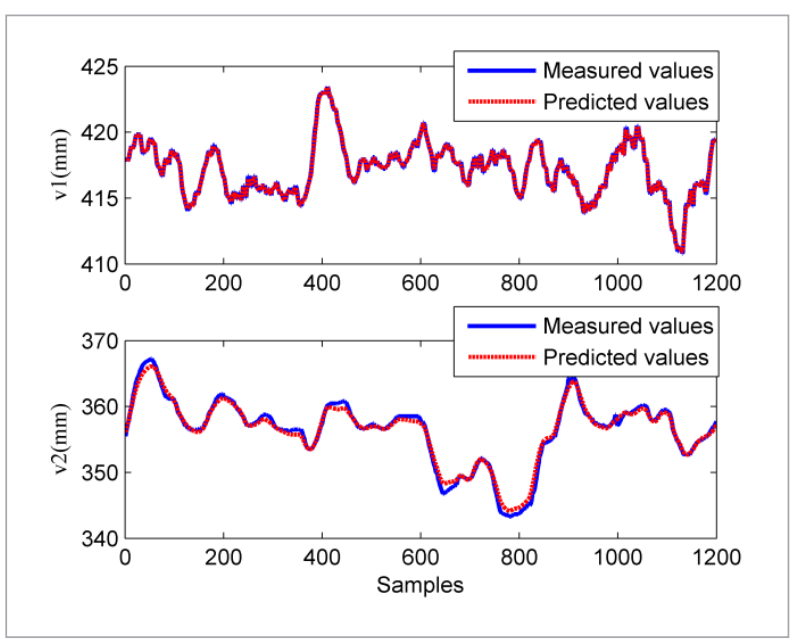

Figure 10

Identification results of pressure model parameters

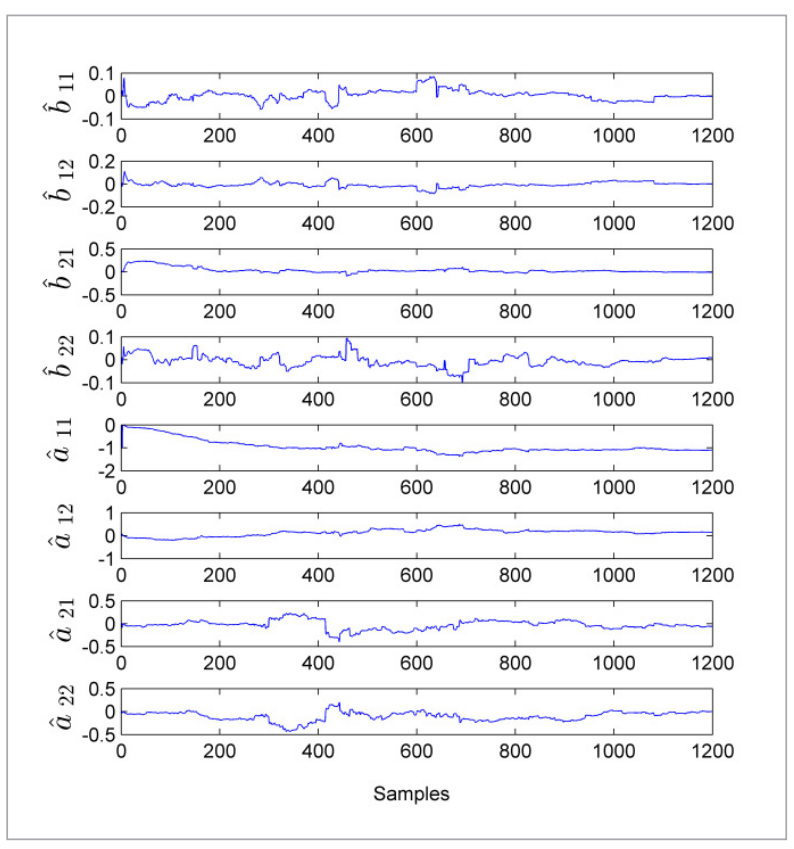

Figure 11

Identification results of Mach number model parameters

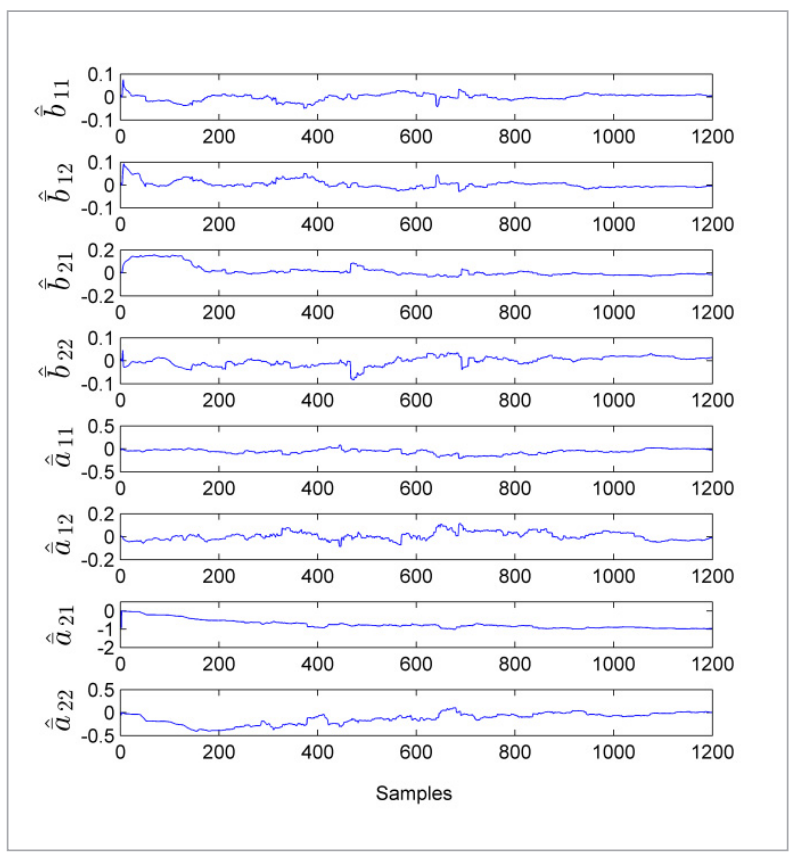

Figure 12

The predicted value, measured values and modelling errors of stagnation pressure
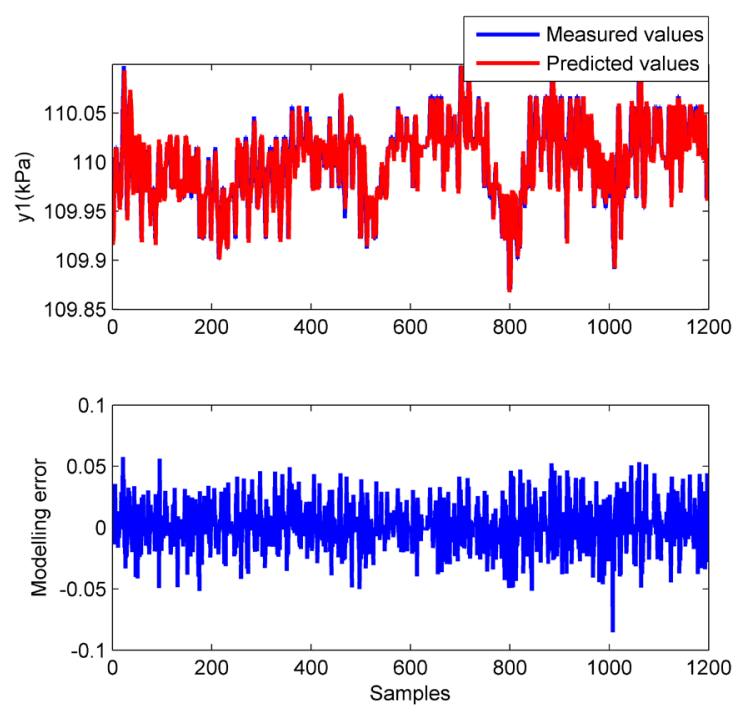


\section{Figure 13}

The predicted value, measured values and modelling errors of Mach number

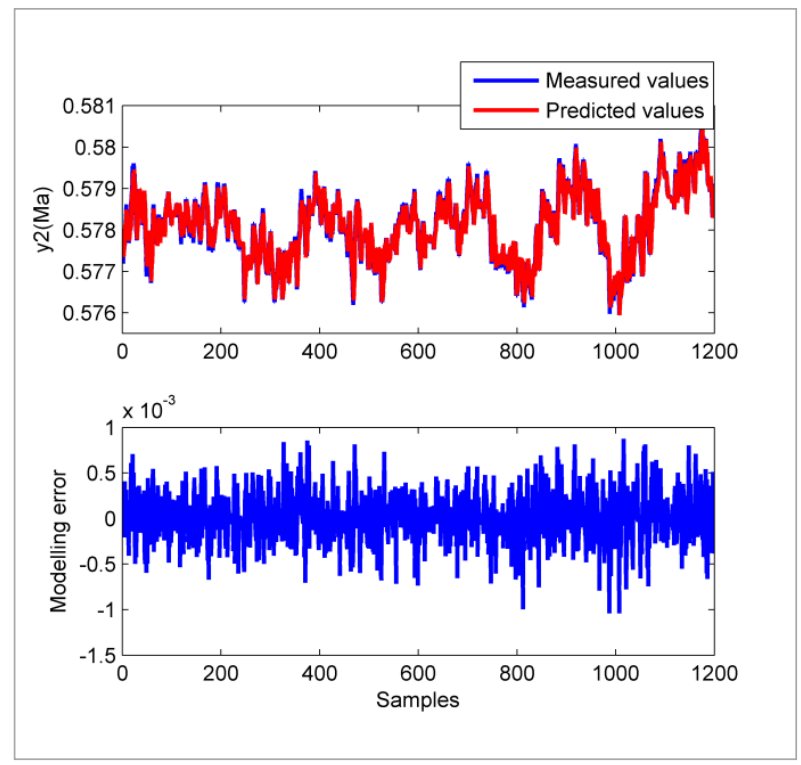

model [14] are shown in Table 2. It is obvious that both RMSE and MAE of the proposed model are better than the conventional model.

\subsection{Verification on the control platform of wind tunnel}

In order to verify the real-time performance of the proposed modeling scheme, further tests on the control platform of the wind tunnel system are carried out. The platform is equipped with several national instrument (NI) modules and created by LabVIEW software. It can be used to test or optimize the model and controller, and thus reduces the cost and risk during the controller design.

The experiments are performed in the following working condition: stagnation pressure $110 \mathrm{kPa}$, Mach number 0.578. The control signals are given to both the obtained model and the actual wind tunnel. Then the measured outputs and the estimated outputs are displayed on the interface of the control platform, as shown in Figs. 14-15.

\section{Conclusions}

In this paper we present a nonlinear block-oriented model for the $2.4 \mathrm{~m}$ wind tunnel. The block-oriented model consists of three parts: the main exhaust valve subsystem is represented as a linear model, the choke finger susystem is described as a pseudo- $\mathrm{H}$ model with input backlash, and the flow field subsystem is considered as a TITO linear model. In order to facilitate the applications of the modeling scheme, the RLS, AW-RLS and H-RLS algorithms are presented for three subsystems. Finally, the results of simulations and control platform experiments show the validity of the proposed modeling scheme.

\section{Acknowledgments}

This work was supported by National Natural Science Foundation of China (61333006). The authors would like to thank the engineers of China Aerodynamics Research and Development Center for supporting the equipment and the data.

\section{Table 2}

Performance criteria for identified block-oriented and conventional models

\begin{tabular}{|c|c|c|c|c|c|}
\hline \multirow{2}{*}{$\begin{array}{c}\text { Working condition } \\
\text { (P0/Ma) }\end{array}$} & Model & \multicolumn{2}{|c|}{ RMSE } & \multicolumn{3}{c}{ MAE } \\
\cline { 2 - 6 } & Block_oriented model & 0.0256 & 0.00033 & 0.0937 & 0.0012 \\
\hline \multirow{3}{*}{$110 / 0.578$} & Conventional model & 0.0287 & 0.0004 & 0.1252 & 0.0026 \\
\cline { 2 - 6 } & ENN model & 0.0023 & 0.0010 & 0.135 & 0.0031 \\
\hline \multirow{2}{*}{$130 / 0.822$} & Block_oriented model & 0.0367 & 0.0005 & 0.1105 & 0.0041 \\
\cline { 2 - 6 } & Conventional model & 0.0391 & 0.0009 & 0.1843 & 0.0059 \\
\cline { 2 - 6 } & ENN model & 0.0045 & 0.0011 & 0.1904 & 0.006 \\
\hline
\end{tabular}


Figure 14

The estimated stagnation pressure from block-oriented model and the measured data

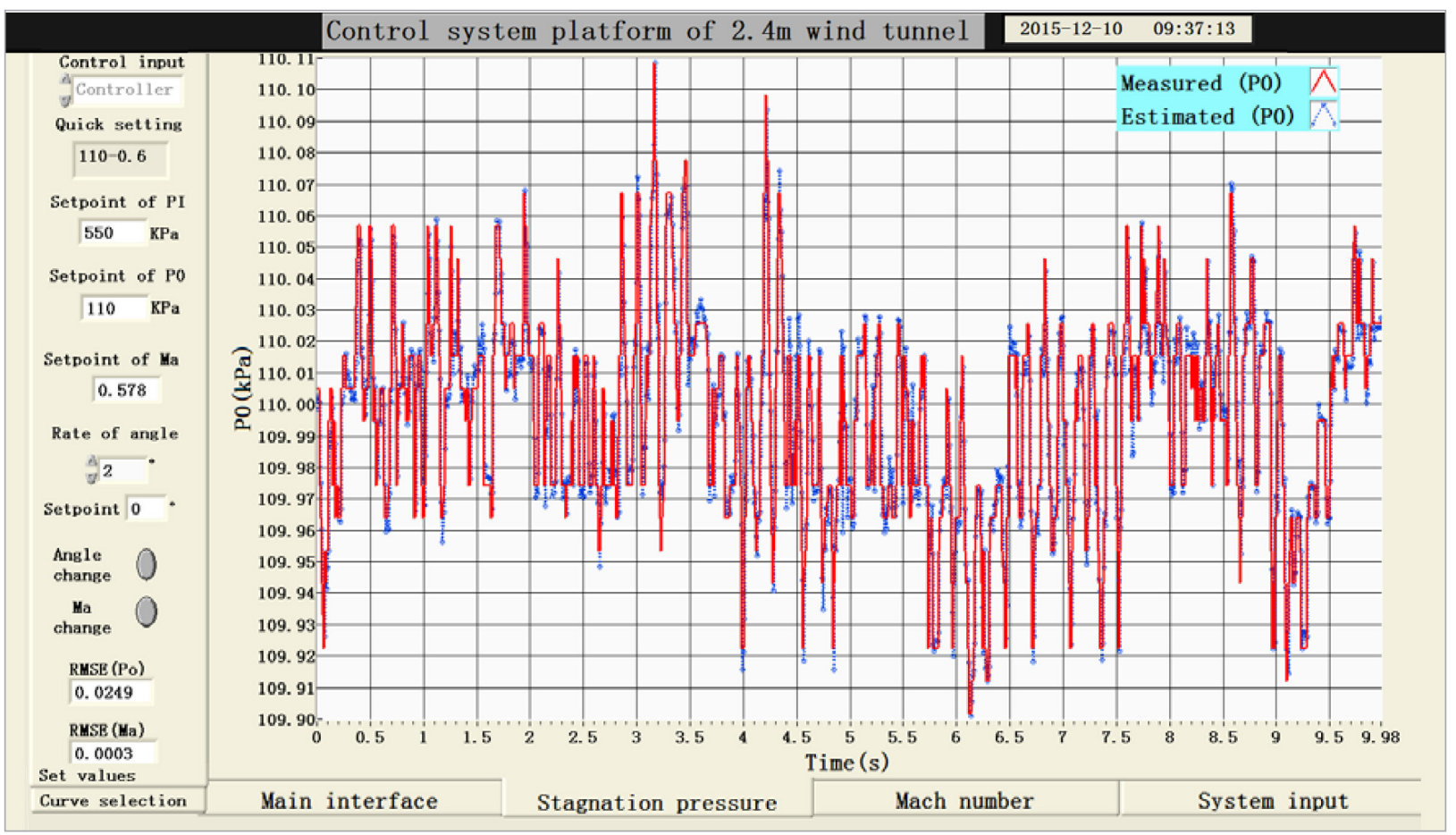

Figure 15

The estimated Mach number from block-oriented model and the measured data

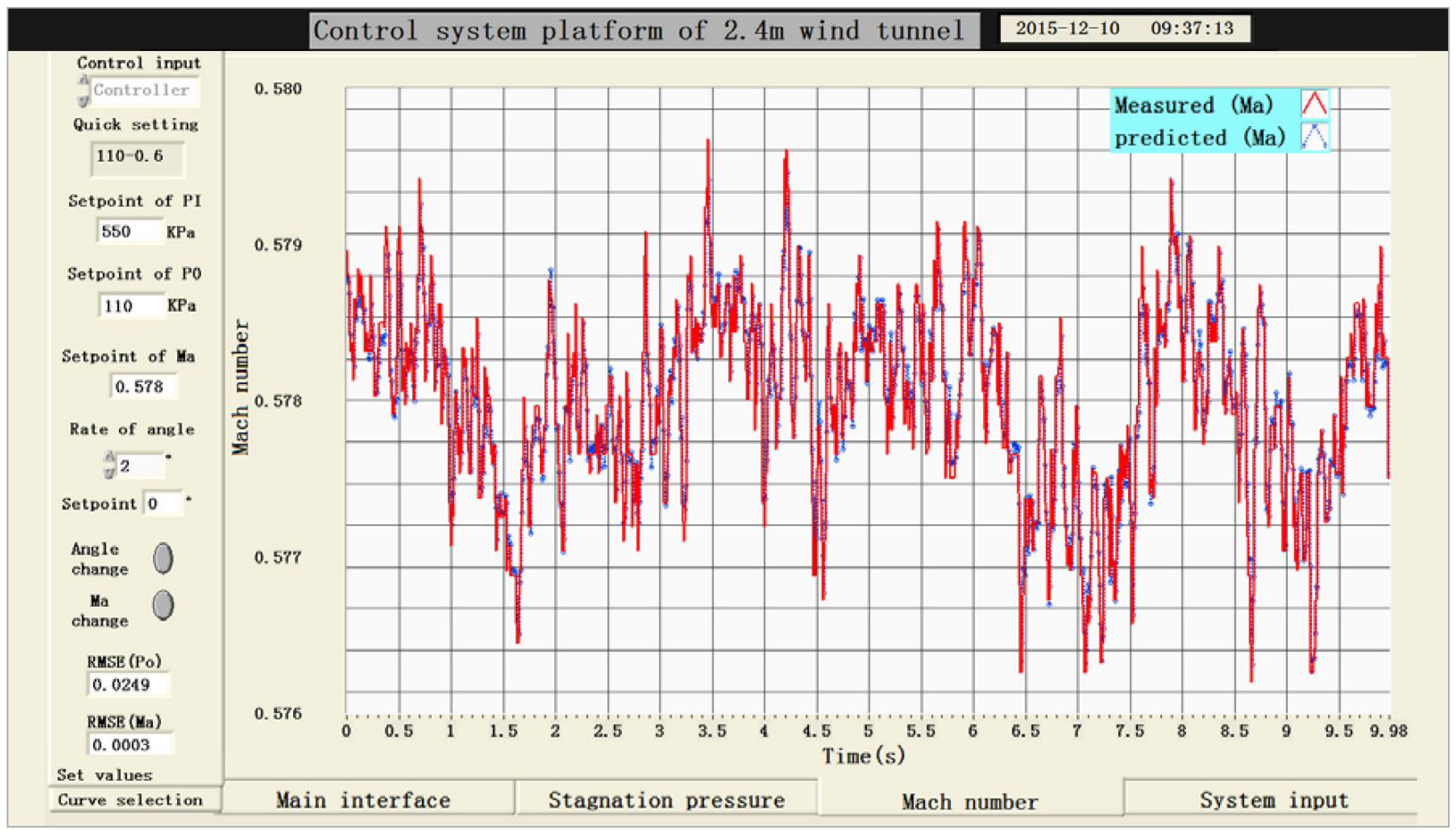




\section{References}

1. Böling, J. M., Seborg, D. E., Hespanha, J. P. Multi-Model Adaptive Control of a Simulated pH Neutralization Process. Control Engineering Practice, 2007, 15(6), 663672. https://doi.org/10.1016/j.conengprac.2006.11.008

2. Cerone, V., Regruto, D. Bounding the Parameters of Linear Systems with Input Backlash. IEEE Transactions on Automatic Control, 2007, 52(3), 531-536. http://dx. doi.org/10.1109/TAC.2007.892375

3. Ding, J., Ding, F., Liu, X. P., Liu,G. Hierarchical Least Squares Identification for Linear SISO Systems with Dual-Rate Sampled-Data. IEEE Transactions on Automatic Control, 2011, 56(11), 2677-2683. http://dx.doi. org/10.1109/TAC.2011.2158137

4. Fang, L., Wang, J., Zhang, Q. Identification of Extended Hammerstein Systems with Hysteresis-Type Input Nonlinearities Described by Preisach Model. Nonlinear Dynamics, 2015, 79(2), 1257-1273. http://dx.doi. org/10.1007/s11071-014-1740-3

5. Giri, F., Bai, E. W. Block-Oriented Nonlinear System Identification. London, Springer, 2010.

6. Hägglund, T. Automatic On-line Estimation of Backlash in Control Loops. Journal of Process Control, 2007, 17(6), 489-499. https://doi.org/10.1016/j.jprocont.2007.01.002

7. Jin, Z. W., Zhao, L., Rao, Z. Z. Mach Number Prediction Models Based on Ensemble Neural Networks for Wind Tunnel Testing. IEEE International Conference on Control and Decision, Chang Sha, China, 31 May - 2 June 2014, 1637-1640. http://dx.doi.org/10.1109/ CCDC.2014.6852430

8. Johansen, T. A., Foss, B. Constructing NARMAX Models Using ARMAX Models. International Journal of Control, 1993, 58(5), 1125-1153. http:// dx.doi. org/10.1080/00207179308923046

9. Kaminskas, V., Liutkevičius, R. Adaptive Fuzzy Control of Pressure and Level. Information Technology and Control, 2009, 38(3), 233-236. http://itc.ktu.lt/index. php/ITC/article/view/12104/6752

10. Li, K., Peng, J. X., Rwin, G. W. A Fast Nonlinear Model Identification Method. IEEE Transactions on Automatic Control, 2005, 50(8), 1211-1216. http://dx.doi. org/10.1109/TAC.2005.852557

11. Ljung, L. System Identification: Theory for the User. Prentice Hall Information and System Sciences Series. Ed: Prentice Hall, New Jersey, 1999.
12. Liu, W., Pokharel, P. P., Principe, J. C. The Kernel Least-Mean-Square Algorithm. IEEE Transactions on Signal Processing, 2008, 56(2), 543-554. http://dx.doi. org/10.1109/TSP.2007.907881

13. Liu, Y., Pan, Y., Sun, Z., Huang, D. Statistical Monitoring of Wastewater Treatment Plants Using Variational Bayesian PCA. Industrial \& Engineering Chemistry Research, 2014, 53(8), 3272-3282. http://dx.doi. org/10.1021/ie403788v

14. Liu, Z. C. Measurement and Control System Design in High and Low Speed Wind Tunnel. National Defense Industry Press, Beijing, 2003.

15. Li, Y., Tong, S., Li, T. Observer-Based Adaptive Fuzzy Tracking Control of MIMO Stochastic Nonlinear Systems with Unknown Control Directions and Unknown Dead Zones. IEEE Transactions on Fuzzy Systems, 2015, 23(4), 1228-1241. http://dx.doi.org/10.1109/TFUZZ.2014.2348017

16. Li, Y., Tong, S. Adaptive Fuzzy Output-Feedback Control of Pure-Feedback Uncertain Nonlinear Systems with Unknown Dead Zone. IEEE Transactions on Fuzzy Systems, 2014, 22(5), 1341-1347. http://dx.doi. org/10.1109/TFUZZ.2013.2280146

17. Merzouki, R., Cadiou, J. C. Estimation of Backlash Phenomenon in the Electromechanical Actuator. Control Engineering Practice, 2005, 13(8), 973-983. https://doi. org/10.1016/j.conengprac.2004.10.016

18. Nordin, M., Gutman, P. O. Controlling Mechanical Systems with Backlash - A Survey. Automatica, 2002, 38(10), 1633-1649. https://doi.org/10.1016/S00051098(02)00047-X

19. Pupeikis, R. On Recursive Parametric Identification of Wiener Systems. Information Technology and Control, 2011, 40(1), 21-28. http://dx.doi.org/10.5755/j01. itc.40.1.189

20. Pan, Y., Er, M. J., Li, X., Yu, H., Gouriveau, R. Machine Health Condition Prediction Via Online Dynamic Fuzzy Neural Networks. Engineering Applications of Artificial Intelligence, 2014, 35, 105-113. http://dx.doi. org/10.1016/j.engappai.2014.05.015

21. Perić, Z., Lukić, J., Nikolić, J., Denić, D. Application of Mean-Square Approximation for Piecewise Linear Optimal Compander Design for Gaussian Source and Gaussian Mixture Model. Information Technology and Control, 2013, 42(3), 277-285. http://dx.doi. org/10.5755/j01.itc.42.3.4349 
22. Rui, W., Qin, J., Ma, Y. A Novel Approach for Modelling of an Injector Powered Transonic Wind Tunnel. IEEE International Conference on Control and Decision, Chang Sha, China, 31 May - 2 June 2014, 1197-1200. http://dx.doi.org/10.1109/CCDC.2014.6852348

23. Seeger, M. Gaussian Processes for Machine Learning. International Journal of Neural Systems, 2004, 14(02), 69-106. https://doi.org/10.1142/S0129065704001899

24. Soeterboek, R. A., Pels, A. F., Verbruggen, H. B., van Langen, G. C. A Predictive Controller for the Mach Number in a Transonic Wind Tunnel. IEEE Control Systems, 1991, 11(1), 63-72. http://dx.doi.org/10.1109/37.103359

25. Vanbeylen, L. Nonlinear LFR Block-Oriented Model: Potential Benefits and Improved, User-Friendly Identification Method. IEEE Transactions on Instrumentation and Measurement, 2013, 62(12), 3374-3383. http:// dx.doi.org/10.1109/TIM.2013.2272868

26. Verstraeten, D., Schrauwen, B., d'Haene, M., Stroobandt, D. An Experimental Unification of Reservoir Com- puting Methods. Neural Networks, 2007, 20(3), 391403. https://doi.org/10.1016/j.neunet.2007.04.003

27. Vörös, J. Modeling and Identification of Systems with Backlash. Automatica, 2010, 46(2), 369-374. https://doi. org/10.1016/j.automatica.2009.11.005

28. Wang, D. Q., Ding, F. Hierarchical Least Squares Estimation Algorithm for Hammerstein-Wiener Systems. IEEE Signal Processing Letters, 2012, 19(12), 825-828. http://dx.doi.org/10.1109/LSP.2012.2221704

29. Yu, F., Mao, Z., Jia, M. Recursive Identification for Hammerstein-Wiener Systems with Dead-Zone Input Nonlinearity. Journal of Process Control, 2013, 23(8), 1108-1115. https://doi.org/10.1016/j.jprocont.2013.06.014

30. Yu, F., Mao, Z., Jia, M., Yuan, P. Recursive Parameter Identification of Hammerstein-Wiener Systems with Measurement Noise. Signal Processing, 2014, 105, 137147. https://doi.org/10.1016/j.sigpro.2014.05.030

\section{Summary / Santrauka}

This paper develops a novel nonlinear block-oriented model for the wind tunnel system. Based on the available signals, the wind tunnel system can be divided into three parts, namely, the exhaust valve loop, the choke finger loop and the flow field. Then the considered plant is described as a nonlinear block-oriented model. The exhaust valve subsystem and the flow field subsystem are both expressed by linear dynamic models, whereas the choke finger subsystem exhibits a nonlinear characteristics and is approximated by a pseudo-Hammerstein model. Based on the above parameterization model, the recursive identification algorithms are presented for three subsystems. Interestingly, the adaptive weighted recursive least squares algorithm is applied to the pseudo-Hammerstein model, and the hierarchical recursive least squares algorithm is used to reduce the computational complexities. Both simulations and experiments are carried out to verify the effectiveness of the proposed method.

Straipsnyje aprašomas naujas netiesinis, į blokus orientuotas modelis vejo tunelio sistemai. Remiantis turimais signalais, vejo tunelio sistemą galima suskirstyti į tris dalis: išmetimo vožtuvo kilpą, droselio kilpą ir srauto lauką. Tokiu atveju nagrinejjamas įrenginys aprašomas kaip netiesinis į blokus orientuotas modelis. Išmetimo vožtuvo posistemè ir srauto lauko posistemè yra išreiškiamos tiesiniais dinaminiais modeliais, o droselio kilpos posistemé demonstruoja būdingas netiesines charakteristikas ir yra aproksimuota pseudo-Hammersteino modeliu. Remiantis aukščiau pateiktu parametrizavimo modeliu, trims posistemėms pateikiami rekursiniai identifikavimo algoritmai. Pseudo-Hamersteino modeliui pritaikomas adaptyvusis svorinis rekursinis mažiausių kvadratų algoritmas, o skaičiavimo sudètingumui sumažinti naudojamas hierarchinis rekursinis mažiausių kvadratų algoritmas. Siūlomo metodo efektyvumui patvirtinti atliktos simuliacijos ir eksperimentai. 